\title{
SUCESSÃO FLORESTAL SECUNDÁRIA NO MUNICÍPIO DE SÃO PEDRO DE ALCÂNTARA, LITORAL DE SANTA CATARINA: ESTRUTURA E DIVERSIDADE
}

\author{
SECONDARY FOREST SUCCESSION IN SÃO PEDRO DE ALCÂNTARA AT THE COAST OF \\ SANTA CATARINA STATE: STRUCTURE AND DIVERSITY
}

\author{
Alexandre Siminski ${ }^{1} \quad$ Marcelo Mantovani $^{1}$ Maurício Sedrez dos Reis ${ }^{2} \quad$ Alfredo Celso Fantini ${ }^{2}$
}

\section{RESUMO}

O processo de sucessão florestal secundária no Litoral de Santa Catarina é caracterizado por estádios sucessionais bem-definidos. Este trabalho foi realizado com o objetivo de caracterizar esses estádios em relação à riqueza de espécies, índice de diversidade (Shannon-Weaver), grupos de densidades, classes diamétricas, e área basal. O estudo foi realizado em uma área situada no município de São Pedro de Alcântara, localizado a $50 \mathrm{~km}$ de Florianópolis, com vegetação característica de Floresta Ombrófila Densa. Foram amostradas seis parcelas de $10 \times 10 \mathrm{~m}$ em cada estádio sucessional, Myrsinietum ${ }^{3}$, Miconietum e Mata Secundária. Foram medidos todos indivíduos de espécies arbóreas e arbustivas com altura superior a 1 metro. O estádio de Myrsinietum, com grande dominância de Myrsine coriacea, se caracterizou pela baixa diversidade de espécies ( $\mathrm{H}=2,09$ nats), com muitos indivíduos de cada espécie nas classes de menor diâmetro $(<10 \mathrm{~cm})$, refletindo em uma baixa área basal $\left(6,99 \mathrm{~m}^{2} / \mathrm{ha}\right)$. No estádio de Miconietum, com dominância de Miconia cinnamomifolia, existe um grande número de indivíduos nas classes de até $20 \mathrm{~cm}$ de DAP, não passando de $35 \mathrm{~cm}$, resultando em uma área basal de 33,67 m²/ha. Nesse estádio, verificou-se um grande número de espécies, com alta diversidade $(\mathrm{H}=3,55$ nats), das quais a maior parte é de ocorrência muito esparsa. No estádio de Mata Secundária, existe um grande número de indivíduos nas classes até $15 \mathrm{~cm}$ de DAP, mas com indivíduos até $52 \mathrm{~cm}$, resultando em uma área basal de $39,11 \mathrm{~m}^{2}$. Nesse estádio, $50 \%$ das espécies é de ocorrência muito esparsa com um índice de diversidade $(\mathrm{H})$ de 3,48 nats. Os resultados obtidos neste trabalho não permitiram o enquadramento dos estádios sucessionais de Myrsinietum, Miconietum e Mata Secundária nos estádios de regeneração definidos pela Resolução n. 04/1994 do CONAMA. As características de cada estádio sucessional demonstram a grande dessemelhança existente entre o estádio Myrsinietum e os estádios Miconietum e Mata Secundária, tanto do ponto de vista estrutural como ecológico. Essas diferenças podem subsidiar estratégias, visando ao uso e à conservação dos recursos florestais.

Palavras-chave: sucessão secundária; riqueza de espécies; estrutura florestal; resolução CONAMA.

\section{ABSTRACT}

The forest succession process in the coast of Santa Catarina State, Brazil, is characterized by easily defined stages. In this paper the were characterized these stages regarding species richness and diversity index (Shannon-Weaver index - SWI), density groups, DBH distribution, and basal area. The study was carried out in the municipality of São Pedro de Alcântara, located $50 \mathrm{~km}$ from the state capital, Florianópolis, where the forest cover is typical of the Brazilian Mata Atlantica. Six 10x10 m plots were measured in each of the succession stages called Myrsinietum, Miconietum, and Secondary Forest. All individuals of tree and shrub species $1 \mathrm{~m}$ or taller were measured. The Myrsinietum stage, with a strong dominance by Myrsine coriacea, was characterized by a small species diversity ( $\mathrm{SWI}=2.09$ nats), with many individuals of each species in the smaller DBH classes $(<10 \mathrm{~cm})$, resulting in a low basal area $\left(6.99 \mathrm{~m}^{2} / \mathrm{ha}\right)$, despite the high density of plants. In the Miconietum stage, dominated by Miconia cinnamomifolia, there is a high number of individuals in the classes up to $20 \mathrm{~cm}$ in DBH, with maximum of $35 \mathrm{~cm}$, resulting in a basal area of $33.67 \mathrm{~m}^{2} / \mathrm{ha}$. In this stage, there was a high number of species with high diversity (SWI $=3.55$ nats), most of them occurring sparsely. In

1. Engenheiro Agrônomo, Mestrando pelo Programa de Pós-Graduação em Recursos Genéticos Vegetais. Núcleo de Pesquisas em Florestas Tropicais, Dep. de Fitotecnia, UFSC, Caixa Postal 476, CEP 88040-900, Florianópolis (SC).

2. Professor do Programa de Pós-Graduação em Recursos Genéticos Vegetais. Núcleo de Pesquisas em Florestas Tropicais, Dep. de Fitotecnia, UFSC, Caixa Postal 476, CEP 88040-900, Florianópolis (SC).

3. O estádio Myrsinietum era denominado por KLEIN (1980) como Rapanietum em razão da fitofisionomia determinada pela espécie Rapanea ferruginea, atualmente Myrsine coriacea.

Recebido para publicação em 20/12/2002 e aceito em 16/3/2004. 
the Secondary Forest stage, there is a high number of trees in the DBH classes up to $15 \mathrm{~cm}$, but some individuals reached more than $52 \mathrm{~cm}$, resulting in a basal area of $39.11 \mathrm{~m}^{2} / \mathrm{ha}$. In this stage, $50 \%$ of the species occur very sparsely, with a diversity index $(\mathrm{H})$ of 3.48 nats. According to the results of this study it is not possible to conform the succession stages of Myrsinietum, Miconietum e Mata Secundária with the regeneration stages defined by the Resolution $n^{\circ} 04 / 1994$ of CONAMA. The characteristics of each succession stage showed the large dissimilarity between the Myrsinietum and the other stages from the point of view of structure as well as ecological aspects. These dissimilarities can subsidize strategies of use and conservation of local forest resources.

Key words: succession; species richness; forest structure; CONAMA resolution.

\section{INTRODUÇÃO}

As florestas tropicais em todo o mundo continuam ameaçadas pela degradação descontrolada e pela sua conversão para outros tipos de uso da terra, sob a influência da crescente demanda por produtos florestais, da expansão agrícola e do mau manejo dos recursos naturais existentes. Os impactos da perda da biodiversidade pela degradação das florestas aparecem sob a forma de erosão do solo, dano aos habitats silvestres e degradação das áreas de bacias, deterioração da qualidade da vida e redução das opções de usos dos recursos para a promoção do desenvolvimento local.

A Floresta Ombrófila Densa é considerada uma formação vegetacional complexa e heterogênea, fato constatado pelas inúmeras comunidades e associações de espécies que somente são encontradas nesses ambientes. Essa tipologia faz parte do que se denomina de Mata Atlântica (Decreto 750/93), que se estende por quase toda a faixa litorânea do Brasil, do Rio Grande do Norte ao Rio Grande do Sul e que representava originalmente $12 \%$ da cobertura florestal no território nacional. Atualmente, a cobertura remanescente dessa floresta se restringe a 7,3\% da área original (Lino, 1991, Fundação SOS Mata Atlântica e INPE, 2000).

Segundo Viana e Tabanez (1996), a Mata Atlântica é o ecossistema tropical em estado mais crítico de degradação em todo mundo. Atualmente, a maioria dos seus remanescentes está representada apenas por fragmentos de formações florestais secundárias. Os poucos núcleos que ainda podem ser caracterizados como florestas primárias se concentram em regiões de maior altitude e de difícil acesso (Reis et al., 1995).

No estado de Santa Catarina, esse ecossistema foi muito alterado com a conversão para a agricultura e nos locais onde essa atividade foi abandonada surgiram formações secundárias originando uma paisagem constituída por mosaicos de vegetação em vários estádios sucessionais (Queiroz, 1994). A vegetação secundária pode ser definida como sendo um conjunto de comunidades vegetais que surgem após um impacto natural ou antrópico. É caracterizado por estádios sucessionais bem-demarcados e que tendem a reconstituir a vegetação original, sendo um mecanismo de auto-renovação das florestas tropicais por meio da cicatrização de locais perturbados (Klein, 1980; Kageyama e Castro, 1989).

A correta definição do estádio sucessional de uma comunidade arbórea tem implicações em diferentes campos das atividades florestais e das políticas ambientais. Com o objetivo de orientar os procedimentos de licenciamento de atividades em áreas florestais a Resolução CONAMA n. 010 de 1993, estabeleceu como parâmetros básicos para análise dos estádios de sucessão da Mata Atlântica a caracterização da fisionomia; estratos predominantes; distribuição diamétrica e altura; existência, diversidade e quantidade de epífitas; existência, diversidade e quantidade de trepadeiras; presença, ausência e características da serapilheira; subbosque; diversidade e dominância de espécies; espécies vegetais indicadoras. O detalhamento dos parâmetros estabelecidos nessa resolução, bem com os valores mensuráveis, tais como altura e diâmetro, para o estado de Santa Catarina, foram definidos pela Resolução n. 04/1994 do CONAMA.

A existência dessas diretrizes fornece uma base técnica para diferenciação dos estádios, mas ainda não permite que se o faça de forma inequívoca, ocorrendo tradicionalmente a classificação de forma subjetiva e exigindo grande experiência por parte do técnico. Adicionalmente, os produtores rurais se dizem fortemente prejudicados, alegando que os parâmetros estabelecidos foram determinados sem nenhum estudo aprofundado sobre o processo de sucessão florestal, e que suas restrições seriam responsáveis pela intensificação do processo de êxodo rural, uma vez que comprometeram a continuidade do sistema produtivo da região 
(Siminski, 2002).

Este trabalho foi realizado com o objetivo de caracterizar tais estádios em relação à riqueza de espécies, grupos de densidades, classes diamétricas, estimativa da biodiversidade e a área basal em uma área representativa de vegetação secundária na região de São Pedro de Alcântara. Essas informações podem fundamentar propostas que busquem traçar um paralelo com as informações existentes na legislação, buscando identificar os vazios nas informações requeridas sobre $o$ assunto.

\section{MATERIAIS E MÉTODOS}

\section{Descrição da área}

A área está situada no município de São Pedro de Alcântara (SC), entre os paralelos $27^{\circ}$ e $28^{\circ} \mathrm{S}$ e os meridianos $48^{\circ}$ e $49^{\circ} \mathrm{W}$, localizada a $50 \mathrm{~km}$ de Florianópolis, litoral de Santa Catarina. O clima da região é classificado como $\mathrm{Cfa}$, mesotérmico úmido com verão quente definido. A temperatura média anual é de $20^{\circ} \mathrm{C}$, sendo a média de temperatura do mês mais quente é de $25^{\circ} \mathrm{C}$ (mês de janeiro) e a temperatura do mês mais frio é de $16^{\circ} \mathrm{C}$. A precipitação anual na região é de $1390 \mathrm{~mm}$, bem-distribuída durante o ano (Ide, et al., 1980). O solo predominante da região é o Argissolo Vermelho Amarelo Distrófico típico, anteriormente denominado Podzólico Vermelho Amarelo Distrófico (EMBRAPA, 1999). O relevo da região é fortemente ondulado com altitude média de $300 \mathrm{~m}$ (Santa Catarina, 1973).

A vegetação original do local, segundo Klein et al. (1986) e Veloso et al. (1991), é característica de Floresta Ombrófila Densa, tendo sofrido exploração mais intensiva na década de 50 e atualmente se encontra predominantemente num estádio avançado de regeneração da vegetação, segundo a definição proposta pela Resolução n. 04/1994 do CONAMA.

\section{Metodologia}

Foram amostradas 18 parcelas de 10x10 m $\left(1800 \mathrm{~m}^{2}\right)$ em diferentes propriedades rurais com área total florestal não-mensurada, sendo seis unidades amostrais $\left(600 \mathrm{~m}^{2}\right)$ em áreas características de estádios sucessionais diferenciados.

Para a classificação dos estádios sucessionais, empregou-se análise fitofisionômica prévia, baseado nos trabalhos de Klein (1979 e 1980). Como a composição florística da área de estudo se assemelha a área do estudo de Klein no Vale do Itajaí-SC, manteve-se a nomenclatura que identifica os estádios sucessionais partindo da espécie que ocorre de forma dominante. Dessa forma, passou-se a identificar cada estádio pela proposta de Klein (1980): Capoeira com a espécie dominante Myrsine coriacea - Myrsinietum; Capoeirão com a espécie dominante Miconia cinnamomifolia - Miconietum; e Mata Secundária quando não há dominância, sobre a fitofisionomia, de uma única espécie.

Em cada unidade amostral foram medidos todos os indivíduos de espécies arbóreas e arbustivas com altura superior a um metro, para os quais foram registrados os seguintes dados: diâmetro à altura do peito a 1,30 m (DAP) mensurando todas as plantas acima de $1 \mathrm{~cm}$ de diâmetro, com a utilização de paquímetro; a altura total e do fuste, com régua dendrométrica; e feita a identificação em nível de família, gênero e espécie. Os dados de densidade absoluta, número de plantas por hectare, DAP médio, altura média e área basal, foram agrupados em tabelas com DAP $\geq 1 \mathrm{~cm}$ e $\geq 5 \mathrm{~cm}$, para permitir a comparação com outros trabalhos que utilizam DAP $\geq 5 \mathrm{~cm}$ como critério de amostragem.

A identificação das espécies mais comuns foi feita in loco. Para as outras espécies, procedeu-se à coleta de material botânico que foi etiquetado, prensado, secado e enviado para identificação. O material botânico coletado foi identificado pelo Engenheiro Agrônomo Ademir Roberto Ruschel.

Para cada estádio sucessional, foram caracterizados: a riqueza de espécies, os grupos de densidade, a densidade absoluta (soma das parcelas), a classe diamétrica, a área basal média, além da estimativa da biodiversidade.

Os grupos de densidade foram adaptados de Lisboa (2001), em que: MC = Muito comum (espécies com densidade superior a cem indivíduos na área amostrada de $600 \mathrm{~m}^{2}$ ); $\mathrm{C}=\mathrm{Comum}$ (espécies com densidade 
entre vinte e 99 indivíduos); $\mathrm{PC}=$ Pouco comum (espécies com densidade entre seis e 19 indivíduos). $\mathrm{E}=$ Esparsas (são espécie com densidade entre três e cinco indivíduos); $\mathrm{ME}=$ Muito esparsas (espécies com densidade até 2 indivíduos).

Na estimativa da biodiversidade alfa, foi empregado o índice de Shannon-Weaver (H) (Odum, 1983). A equitabilidade de Pielou (1975) ou casualidade da diversidade comunitária foi estimada pelo quociente do índice de diversidade de Shannon-Weaver pelo logaritmo natural do número de espécies encontradas.

\section{RESULTADOS E DISCUSSÃO}

$\mathrm{Na}$ fase de Myrsinietum, as plantas se apresentam com DAP médio de 4,2 cm, altura média de 4,4 $\mathrm{m}$ e uma área basal de $6,99 \mathrm{~m}^{2} /$ ha (Tabela 1). Do total de plantas, $46,3 \%$ (137) tiveram DAP acima de $5 \mathrm{~cm}$, representando um DAP médio de $6,8 \mathrm{~cm}$, com uma altura média de $4,6 \mathrm{~m}$ e área basal de 5,06 $\mathrm{m}^{2} / \mathrm{ha}$ (Tabela 2). Os dados encontrados nessa fase aproximam-se do estádio inicial de regeneração, propostos pela resolução do CONAMA para os parâmetros de DAP e área basal (Tabela 3), que estabelece DAP médio de $8 \mathrm{~cm}$ e área basal até $8 \mathrm{~m}^{2}$. Entretanto, para a altura total média, os dados foram superiores aos $4 \mathrm{~m}$ estabelecidos pela resolução para esse mesmo estádio.

TABELA 1: Valores mensurados para o estrato arbóreo (DAP $\geq 1 \mathrm{~cm}$ ) em três estádios sucessionais, no município de São Pedro de Alcântara - SC, 2002.

TABLE 1: Forest structure parameters $(\mathrm{DBH} \geq 1 \mathrm{~cm})$ for three different successional stages in the Mata Atlântica of São Pedro de Alcântara-SC, 2002.

\begin{tabular}{l|c|c|c|c|c}
\hline Estádio Sucessional & $D A$ & NP/ha & DAP & Alt $(\mathrm{m})$ & $\mathrm{AB}\left(\mathrm{m}^{2} / \mathrm{ha}\right)$ \\
\hline Myrsinietum & 296 & 4.933 & $4,2(0,59)$ & $4,4(0,55)$ & $6,99(0,42)$ \\
Miconietum & 553 & 9.217 & $6,3(1,23)$ & $4,6(1,54)$ & $33,67(1,28)$ \\
Mata Secundária & 452 & 7.533 & $6,1(0,69)$ & $4,5(0,78)$ & $39,11(1,79)$ \\
\hline
\end{tabular}

Em que: $\mathrm{DA}=$ Densidade absoluta; NP/ha= Número de plantas por hectare; DAP = Diâmetro à altura do peito médio. Alt $=$ Altura média; $\mathrm{AB}=$ Área basal média. Os valores entre parênteses correspondem ao desvio-padrão.

TABELA 2: Valores mensurados para o estrato arbóreo (DAP $\geq 5 \mathrm{~cm}$ ) em três estádios sucessionais, no município de São Pedro de Alcântara - SC, 2002.

TABLE 2: Forest structure parameters $(\mathrm{DBH} \geq 5 \mathrm{~cm})$ for three different successional stages in the Mata Atlântica of São Pedro de Alcântara-SC, 2002.

\begin{tabular}{l|c|c|c|c|c}
\hline Estádio Sucessional & $D A$ & $N P / h a$ & $D A P$ & Alt $(\mathrm{m})$ & $\mathrm{AB}\left(\mathrm{m}^{2} / \mathrm{ha}\right)$ \\
\hline Myrsinietum & 137 & 2.283 & $6,8(0,57)$ & $4,6(0,60)$ & $5,06(0,37)$ \\
Miconietum & 163 & 2.717 & $10,6(1,55)$ & $9,4(2,11)$ & $31,95(1,30)$ \\
Mata Secundária & 115 & 1.917 & $12,9(1,57)$ & $9,8(1,40)$ & $37,31(1,81)$ \\
\hline
\end{tabular}

Em que: $\mathrm{DA}=$ Densidade absoluta; NP/ha= Número de plantas por hectare; DAP = Diâmetro à altura do peito médio. Alt $=$ Altura média; $\mathrm{AB}=$ Área basal média. Os valores entre parênteses correspondem ao desvio-padrão.

Para a fase de Miconietum, o DAP médio foi de $6,3 \mathrm{~cm}$, altura média de 4,5 $\mathrm{m}$ e uma área basal de $33,67 \mathrm{~m}^{2} /$ ha (Tabela 1). Do total de plantas, 29,5\% (163) tiveram DAP acima de $5 \mathrm{~cm}$, representando um DAP médio foi de $10,6 \mathrm{~cm}$, com uma altura média de $9,4 \mathrm{~m}$ e área basal de $31,9 \mathrm{~m}^{2} / \mathrm{ha}$ (Tabela 2). Os dados encontrados nesse estádio se aproximam do estádio médio de regeneração, segundo a resolução do CONAMA, para os parâmetros de DAP e altura total média (Tabela 3), que estabelece DAP médio de $15 \mathrm{~cm}$ e altura total média de até $12 \mathrm{~m}$. Para a área basal, os dados foram superiores aos $15 \mathrm{~m}^{2}$ estabelecidos pela resolução para esse mesmo estádio.

No estádio sucessional Mata Secundária, o DAP médio foi de $6,1 \mathrm{~cm}$, altura média de 4,5 $\mathrm{m}$ e uma área basal de $39,1 \mathrm{~m}^{2} /$ ha (Tabela 1). Do total de plantas, $115(25,4 \%)$ tiveram DAP acima de $5 \mathrm{~cm}$, representando um DAP médio de $12,9 \mathrm{~cm}$, com uma altura média de $9,8 \mathrm{~m}$ e área basal de $37,3 \mathrm{~m}^{2} / \mathrm{ha}$ (Tabela 2). Os dados encontrados neste estádio se aproximam do estádio médio de regeneração, proposto pela resolução do CONAMA para os parâmetros de DAP e altura total média (Tabela 3). Para a área basal, os dados foram superiores aos $20 \mathrm{~m}^{2}$ estabelecidos pela resolução para esse mesmo estádio. 
TABELA 3: Parâmetros quantitativos que definem a vegetação secundária nos estádios inicial, médio e avançado de regeneração da Mata Atlântica, conforme Resolução CONAMA 04/1994.

TABLE 3: Quantitative parameters that define the secondary vegetation in initial, mean and advanced stages of regeneration of Atlantic Rain Forest, accorging to Resolution CONAMA 04/1994.

\begin{tabular}{lccc}
\hline Estádio Sucessional & DAP médio $(\mathrm{cm})$ & Alt média $(\mathrm{m})$ & AB média $\left(\mathrm{m}^{2} / \mathrm{ha}\right)$ \\
\hline Inicial & até 8,0 & até 4,0 & até 8,0 \\
Médio & até 15,0 & até 12,0 & até 15,0 \\
Avançado & até 25,0 & até 20,0 & até 20,0 \\
\hline
\end{tabular}

Em que: $\mathrm{DAP}=$ Diâmetro à altura do peito médio; Alt = Altura média; $\mathrm{AB}=$ Área basal média.

A área basal, quando considerados os indivíduos com DAP acima de $5 \mathrm{~cm}$ (Tabela 2), foi semelhante aos dados encontrados por Tabarelli e Mantovani (1999), em Floresta Atlântica Montana no sudeste do Brasil, para trechos de floresta secundária com 10 anos de regeneração $\left(5 \mathrm{~m}^{2} / \mathrm{ha}\right), 40$ anos de regeneração $(33,4$ $\left.\mathrm{m}^{2} / \mathrm{ha}\right)$, e floresta madura $\left(38,6 \mathrm{~m}^{2} / \mathrm{ha}\right)$.

A distribuição diamétrica no estádio sucessional de Myrsinietum se diferencia dos demais pelo fato que os indivíduos alcançam no máximo 13,6 cm de DAP, com 69\% dos indivíduos na classe diamétrica de até $5 \mathrm{~cm}$ de DAP (Figura 1). Os estádios Miconietum e Mata Secundária possuem para as classes diamétricas até $10 \mathrm{~cm}, 79,7 \%$ e $84 \%$ respectivamente, sendo apenas encontrados indivíduos com mais de $35 \mathrm{~cm}$ de DAP no estádio de Mata Secundária (Figura 1).

Dentro da área amostrada de $600 \mathrm{~m}^{2}$ do estádio sucessional de Myrsinietum, foram registrados 296 indivíduos, pertencentes a 24 espécies, 21 gêneros e 14 famílias. Do total de indivíduos, 124 são da espécie Myrsine coriacea (capororoca), da família Myrsinaceae. Esta espécie é considerada pela Resoluçãon. 04/1994 do CONAMA como uma espécie indicadora do estádio médio de regeneração na Floresta Ombrófila Densa. Para o estádio sucessional de Miconietum estes números foram de 553 indivíduos, pertencentes a 69 espécies, cinqüenta gêneros e 35 famílias. Destacaram-se os gêneros Euterpe com 77 indivíduos, Psychotria com 65 indivíduos, Miconia com 35 indivíduos e Cyathea com 26 indivíduos. As famílias com maior número de indivíduos foram: Arecaceae, Myrtaceae, Rubiaceae e Melastomataceae. Tanto o Euterpe edulis Martius, quanto a Miconia cinnamomifolia (DC) Naudin são indicadoras do estádio avançado de regeneração da Floresta Ombrófila Densa pela Resolução n. 04/1994.do CONAMA.

Na Mata Secundária, esses valores foram de 452 indivíduos distribuídos em 63 espécies, 48 gêneros e 29 famílias (Tabela 4). Nesse estádio, destacaram-se os gêneros Euterpe com 43 indivíduos, Geonoma com 41 indivíduos, e Mollinedia com 26 indivíduos. As famílias, que apresentam maior número de indivíduos, foram: Arecaceae, Myrtaceae, Rubiaceae e Monomiaceae.

A riqueza florística encontrada nos estádios Miconietum e Mata Secundária foi semelhante àquela encontrada por Vaccaro et al. (1999) e por Longhi et al. (2000) em área de Floresta Estacional Decidual. 


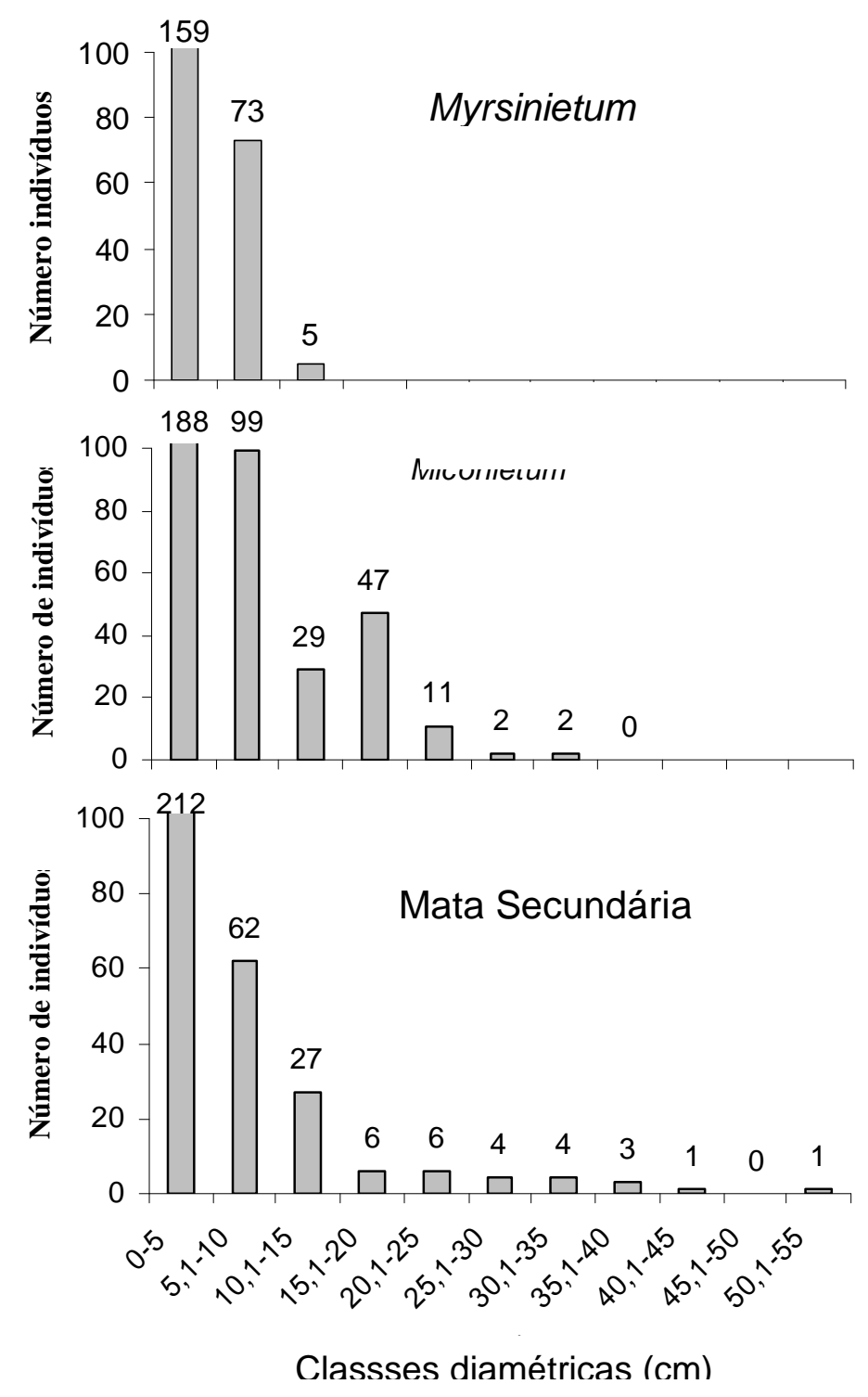

FIGURA 1: Distribuição de classe diamétrica do estrato arbóreo em três estádios de sucessão na Floresta Ombrófila Densa, no município de São Pedro de Alcântara - SC, 2002.

FIGURE 1: DBH distribuition in three different successional stages in the Mata Atlântica of São Pedro de Alcântara-SC, 2002.

TABELA 4: Dados de riqueza de espécies, gêneros e famílias nos três estádios sucessionais com seus respectivos números de indivíduos, em São Pedro de Alcântara, 2002.

TABLE 4: Tree richness in three different successional stages in the Mata Atlântica of São Pedro de Alcântara-SC, 2002.

\begin{tabular}{|c|c|c|c|}
\hline Família Botânica/Nome Científico & Myrsinietum & Miconietum & Mata Secundária \\
\hline \multicolumn{4}{|l|}{ Annonaceae } \\
\hline Duguetia lanceolata St. Hil. & & & 5 \\
\hline Guatteria cf. australis St. Hil. & & 1 & \\
\hline Rollinia sericea $\mathrm{R}$. E. Fries & & 5 & \\
\hline Rollinia sylvatica (St. Hil.) Mart & & & 1 \\
\hline Rollinia sp. & & 5 & \\
\hline
\end{tabular}


TABELA 4: Continuação ...

TABLE 4: Continued ...

Família Botânica/Nome Científico Myrsinietum

Miconietum

Mata Secundária

Xylopia brasiliensis Spreng. 13

Apocynaceae

Aspidosperma cf. parvifolium (Müll.Arg.) A. DC.

Aquifoliaceae

Ilex theezans Mart.

Ilex sp.

1
$8 \quad 5$

Araliaceae

Schefflera angustissima (Marc.) Sobral

Arecaceae

Bactris lindmaniana Drude ex Lindman

Euterpe edulis Mart.

Geonoma gamiova Barb. Rodr.

Asteraceae

Baccharis sp.

Piptocarpha angustifolia Dusén

Vernonia discolor (Spreng.) Less.

Bignoniaceae

Jacaranda micrantha Cham.

Tecoma umbellata (Sond.) Sand.

Burseraceae

Protium kleinii Cuatrec.

Caesalpiniaceae

Copaifera trapezifolia Hayne

Zollernia ilicifolia Vog.

Indeterminada sp1.

Chrysobalanaceae

Hirtella hebeclada Moricand ex A. DC.

Clethraceae

Clethra scabra Pers.

Clusiaceae

Clusia sp.

Clusia parviflora (Saldanha) Engler

Garcinia gardneriana (Planch. \& Triana) Zappi

Cunoniaceae

Weinmania humilis Engler

6

Cyatheaceae

Alsophila sp.

Cyathea schanschin Mart.

3

Cyatheaceae

Cyathea sp.

Cyathea vestita Mart.

Elaeocarpaceae

Sloanea guianensis (Aubl.) Benth.

Sloanea sp.

Euphorbiaceae

Alchornea sidifolia Müll. Arg.
18

5

6

$11 \quad 9$

2
7

(n)

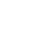

3

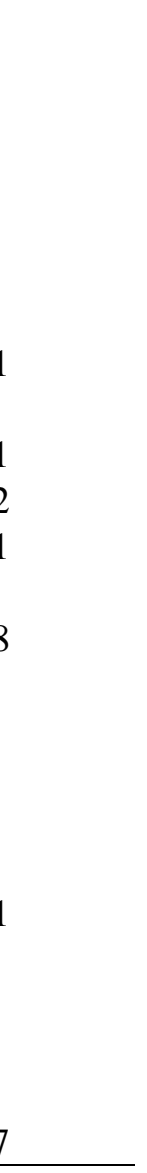

6
9
1

Continua ... 
TABELA 4: Continuação ...

TABLE 4: Continued ...

\begin{tabular}{l|c|c|c}
\hline Família Botânica/Nome Científico & Myrsinietum & Miconietum & Mata Secundária \\
\hline Alchornea triplinervia (Spreng.) M. Arg. & 7 & 3 & 1 \\
\hline Hyeronima alchorneoides Fr. Allem. & 2 & 9 & 1 \\
Pera cf. glabrata (Schott.) Baillon & & 5 & 1 \\
Pera sp. & & 2 & 1 \\
Pousandra morisiana (Casar.) Radlk. & & 1 & \\
Fabaceae & & 1 & \\
Andira anthelma (Vell.) Macbr. & & 1 & \\
Lonchocarpus sp. & & 1 & \\
Indeterminada sp2 & & 4 & \\
Flacourtiaceae & & 2 & \\
Casearia cf. decandra Jacq. & & 2 & \\
Casearia sylvestris Sw. & & & \\
Casearia sp. & & & \\
Indeterminada sp3 & & &
\end{tabular}

Lauraceae

Cryptocayia cf.moschata Mez \& Mart

Endlicheria paniculata (Spr.) Macbr.

Nectandra leucothyrsus Meissner

Nectandra oppositifolia Nees

Nectandra sp.

Ocotea catharinensis $\mathrm{Mez}$

Ocotea sp

Indeterminada $\mathrm{sp} 4$

Indeterminada $\mathrm{sp} 5$

Indeterminada sp6

Magnoliaceae

Talauma ovata St. Hil.

Melastomataceae

Leandra sp.

25

Miconia cabucu Hoehme

Miconia cinnamomifolia (DC) Naudin

Miconia cubatanensis Hoehne

Miconia rigidiuscula Cogn.

Mouriri chamissoniana Cogn.

Tibouchina sellowiana (Cham.) Cong.

Indeterminada sp7

Indeterminada sp8

13

Meliaceae

Cabralea canjerana (Vell.) Mart.

Cedrela fissilis Vell.

Guarea cf macrophylla Vahl.

Guarea sp.

Trichilia cf. elegans A. Juss.

25

6

2

2

1

5

3

3

4

5

4

Trichilia sp.

Indeterminada sp9

Mimosaceae 
TABELA 4: Continuação ...

TABLE 4: Continued ...

\begin{tabular}{l|c|l|c}
\hline Família Botânica/Nome Científico & Myrsinietum & Miconietum & Mata Secundária \\
\hline Inga sessilis (Vell.) Mart. & & & 1 \\
\hline Mimosa bimucronata (DC.) O. Ktze. & 1 & 1 & \\
\hline
\end{tabular}

Monimiaceae

Mollinedia triflora (Spreng.) Tul.

Mollinedia sp.

Moraceae

Brosimum lactescens (S.Moore) C.C. Berg.

Ficus sp.

Sorocea bonplandii (Baillon) Berg.

Myristicaceae

Virola bicuhyba Schott.

Myrsinaceae

Myrsine coriacea (Swartz) R. B. ex Roemer \&

Schultz

Myrsine parvula A. DC.

Myrcine umbellata Mat Ex. DC.

Myrsine sp.

Myrtaceae

Gomidesia spectabilis (DC.) Berg

Marlierea cf. eugeniopsoides (Kaus. \& Legr.) Legr.

Myrcia gracilis Berg.

Mycia rostrata DC.

Psidium cattleyanum Sabine

Indeterminada sp10

Indeterminada sp1 1

Indeterminada sp12

Indeterminada sp13

Indeterminada sp14

Indeterminada sp15

4

Indeterminada sp16

3

2

3

Indeterminada sp17

Nyctaginaceae

Guapira opposita (Vell.) Reitz

Pisonia cf. ambigua Heimer

Nyctaginaceae

Indeterminada sp18

Ochnaceae

Ouratea cf. paviflora (DC.) Baill.

Olacaceae

Heisteria silvianii Schwacke

Piperaceae

Piper sp.

Piper cernuum Vell.

Piper gaudichaudianum Kunth

Rosaceae

Prunus cf brasiliensis (Cham. \& Schlechtd) D. Dietr. 
TABELA 4: Continuação ...

TABLE 4: Continued ...

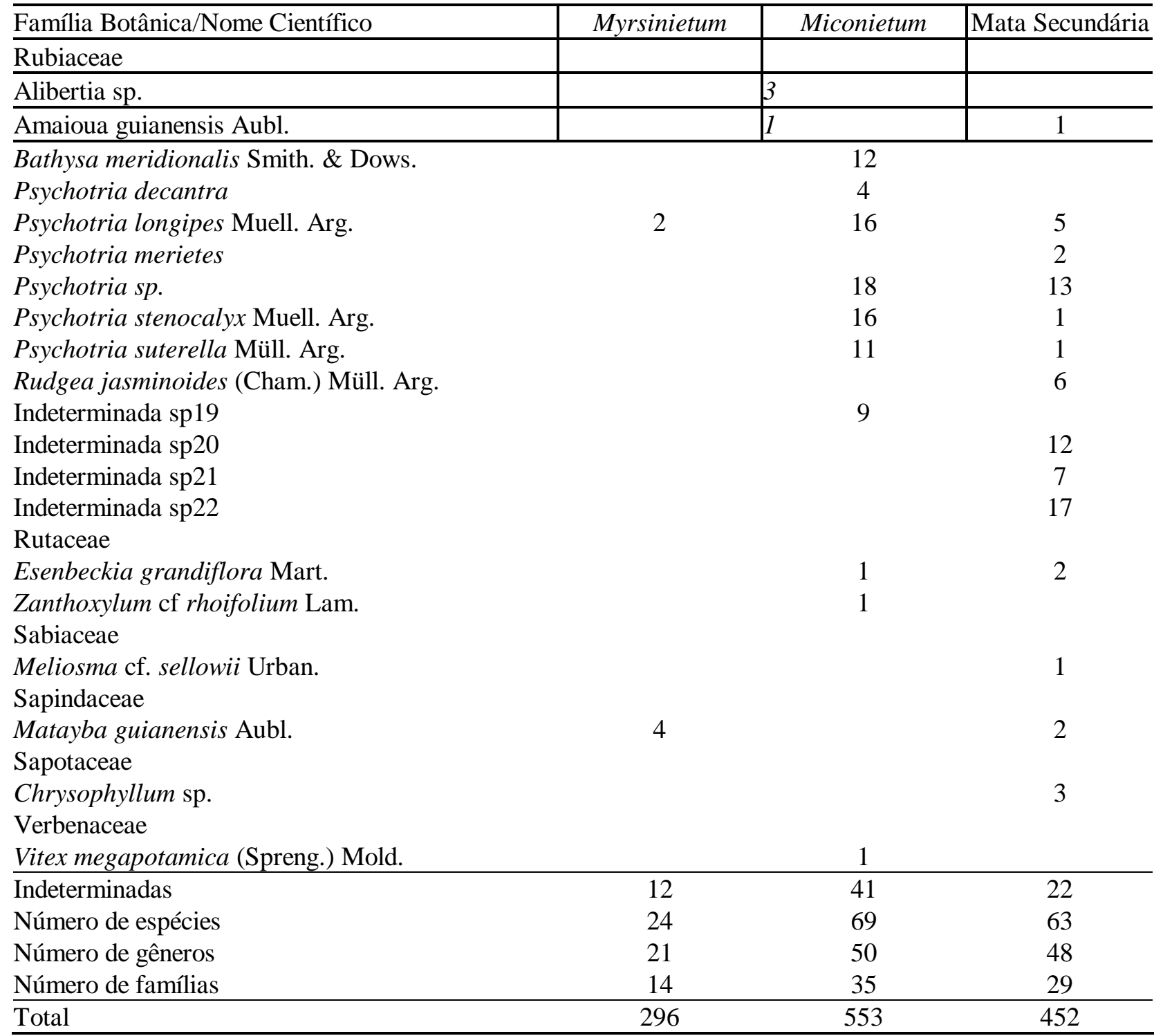

O grupo de densidade das espécies muito comuns (MC) só foi encontrado no estádio de Myrsinietum, onde 124 indivíduos eram da espécie (Myrsine coriacea) (Figura 2). Os estádios de Miconietum e Mata Secundária apresentam respectivamente 47,5\% (28 espécies) e 50\% (29 espécies) das espécies enquadradas como muito esparsa, com densidade de até dois indivíduos na área amostrada (Figura 2).

A amostragem empregada permitiu uma visão dos estádios sucessionais, conseguindo capturar as principais espécies e um percentual de espécies esparsas, mas não atingiu um número máximo de representação, sobretudo para os estádios Miconietum e Mata Secundária, representados por uma curva do número cumulativo de espécies por unidades amostrais ainda ascendente, denotando uma área amostral incapaz de dimensionar todos os parâmetros qualitativos e quantitativos nas áreas estudadas.

A diversidade se refere tanto ao número de espécies (riqueza) de diferentes categorias biológicas, quanto à abundância relativa (equitabilidade) dessas categorias, incluindo alfa $(\alpha)$ diversidade (Índice de Shannon-Weaver) que consiste na variabilidade em nível local, e beta ( $\beta$ ) diversidade que consiste no grau de variação da diversidade de diferentes ecossistemas e habitats (Whittaker, 1960 apud Odum, 1983). 


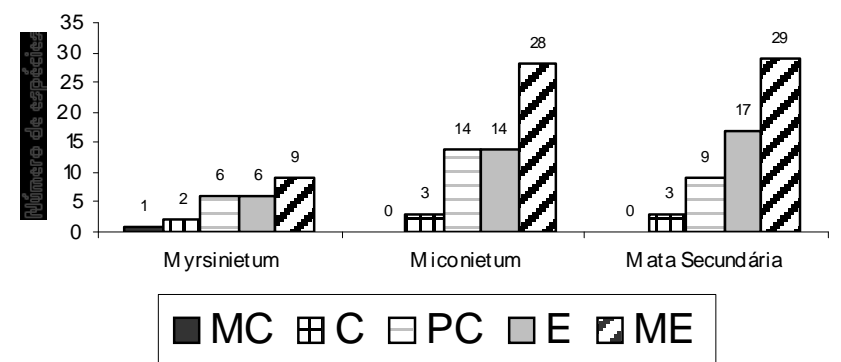

FIGURA 2: Número de espécies por grupo de densidade nos três estádios sucessionais, São Pedro de Alcântara. $(\mathrm{MC}=$ muito comum, $\mathrm{C}=$ comum, $\mathrm{PC}=$ pouco comum, $\mathrm{E}=$ esparsa, $\mathrm{ME}=$ muito esparsa).

FIGURE 2: Number of tree species per groups in three different succession stages in the Mata Atlântica of São Pedro de Alcântara-SC, 2002.

Os resultados indicam um índice de diversidade de 2,09 nats para o estádio de Myrsinietum, 3,55 nats para o estádio de Miconietum e 3,48 nats para o estádio de Mata Secundária (Tabela 5). Nesses dados, observa-se que o índice de diversidade utilizado é fortemente influenciado pelo número de espécies que formam as populações. Em levantamentos fitossociológicos da Floresta Ombrófila Densa, os maiores valores relatados para este índice de diversidade figuram na região sudeste do Brasil, Ubatuba/SP 4,07 nats (Silva e Leitão Filho, 1982) e Juréia/SP 4,31 nats (Mantovani, 1993). Em Santa Catarina os valores mais representativos estão em torno de 3,93 nats, em Azambuja (Silva, 1980).

TABELA 5: Diversidade de espécies em três estádios sucessionais, no município de São Pedro de Alcântara, SC, 2002.

TABLE 5: Diversity index for three different successional stages in the Mata Atlântica of São Pedro de Alcântara-SC, 2002.

\begin{tabular}{l|c|c|c|c|c}
\hline Estádio Sucessional. & Área amostrada $\left(\mathrm{m}^{2}\right)$ & N. Pl. I. & N. espécies & H (nats) & E \\
\hline Myrsinietum & 600 & 280 & 24 & 2,09 & 0,37 \\
Miconietum & 600 & 436 & 69 & 3,55 & 0,58 \\
Mata Secundária & 600 & 298 & 63 & 3,48 & 0,61 \\
\hline
\end{tabular}

Em que: N. Pl. I. = Número de plantas identificadas; H (nats) = Índice de Shannon-Weaver, Ln; E = Equitabilidade de Pielou.

Quanto à equitabilidade, quanto mais avançado o estádio sucessional maior foi seu valor, sendo, respectivamente, de 0,37, 0,58 e 0,61 para os estádios de Myrsinietum, Miconietum e Mata Secundária (Tabela 5). Lisboa (2001) em estudos no Parque Botânico Morro Baú, Ilhota/SC calculou índice de equitabilidade de 0,79 sugerindo que o alfa diversidade estimada pelo índice de Shannon-Weaver esteja próximo ao máximo esperado.

\section{CONCLUSÕES}

As características de cada estádio sucessional demonstram a grande diferença existente entre o estádio Myrsinietum e os estádios Miconietum e Mata Secundária, tanto do ponto de vista estrutural quantitativo (DAP, área basal, altura) e qualitativo (número de famílias, gêneros e espécies), como do ponto de vista ecológico (equitabilidade, Índice de Shannon-Weaver). Essas diferenças são importantes indicativos para definição de estratégias, visando o uso e a conservação dos recursos florestais.

O estádio Myrsinietum é bastante homogêneo e facilmente identificável, caracterizando-se por possuir poucas espécies e um baixo índice de diversidade, podendo ser um referencial prático, em processos de vistoria técnica para avaliar os pedidos de supressão, mais condizente com as necessidades de uso da terra e a conservação dos remanescentes florestais. A prioridade de conservação dos estádios Miconietum e Mata Secundária está relacionada com sua maior diversidade, estando próximas aos índices de uma floresta primária. Entretanto, para que essa perspectiva torne-se viável, faz-se necessário o uso dessa diversidade pelo 
manejo, dentro da proposta de múltiplo uso dos recursos. Destacam-se, dentro dessa concepção, os recursos não-madeiráveis, pelo menor impacto resultante de sua exploração, como o palmito (Euterpe edulis), geonoma (Geonoma gamiova), xaxim (Cyathea sp.), bicuíba (Virola bicuhyba) entre outras espécies com potencial.

Os resultados obtidos neste trabalho não permitiram o enquadramento dos parâmetros dos estádios sucessionais de Myrsinietum, Miconietum e Mata Secundária em um único estádio de regeneração, como definido pela Resolução n. 04/1994 do CONAMA, observa-se uma certa discrepância sobretudo nas variáveis DAP médio, altura total média e área basal média com as espécies indicadoras para cada estádio. Essas diferenças estão relacionadas ao não-fornecimento de um limite diamétrico mínimo de inclusão, impossibilitando seu uso para diferenciação dos estádios.

Essa dificuldade acaba contrapondo justamente o objetivo da resolução de definir vegetação primária e secundária nos estágios inicial, médio e avançado de regeneração da Mata Atlântica, a fim de orientar os procedimentos de licenciamento de atividades florestais no estado de Santa Catarina.

\section{AGRADECIMENTOS}

Ao Núcleo em Florestas Tropicais, pelo fornecimento de materiais de campo e recursos humanos, em destaque os acadêmicos Cristiano Moreira Raimundo e Ricardo Bittencourt. Ao Professor Ademir Reis e Rubens Onofre Nodari, pelas sugestões e discussões. Ao CNPq, pelo apoio financeiro (Processo número 420089/00-4).

\section{REFERÊNCIAS BIBLIOGRÁFICAS}

CONSELHO NACIONAL DO MEIO AMBIENTE. Define vegetação primária e secundária nos estágios inicial, médio e avançado de regeneração da Mata Atlântica em cumprimento ao disposto no artigo $6^{\circ}$ do Decreto 750 , de 10 de fevereiro de 1993, na Resolução CONAMA nº10, de 01 de outubro de 1993. Resolução n.004, de 04 de maio de 1994. Lex: coletânea da legislação ambiental aplicável no estado de Santa Catarina. Florianópolis: FATMA, 2002. p.436-438.

EMBRAPA. Centro Nacional de Pesquisa de Solos (Rio de Janeiro-RJ). Sistema brasileiro de classificação de solos Brasília, 1999. 412p.

FUNDAÇÃO S.O.S. MATA ATLÂNTICA ; INSTITUTO NACIONAL DE PESQUISAS ESPACIAIS; INSTITUTO SOCIOAMBIENTAL. Atlas da evolução dos remanescentes florestais e ecossistemas associados no domínio da Mata Atlântica no período 1995-2000. São Paulo, 2000.

IDE, B.Y. et al. Zoneamento agroclimático do Estado de Santa Catarina: $2^{\text {a }}$ Etapa. Florianópolis: EMPASC, 1980. 106p.

KAGEYAMA, P.Y.; CASTRO, C. Sucessão secundária, estrutura genética e plantações de espécies nativas. IPEF, n. 41/42, p. 83-93, 1989.

KLEIN, R.M. Ecologia da flora e vegetação do Vale do Itajaí. Sellowia, Itajaí, v.32, n.32, p.164-369, nov. 1980.

KLEIN, R.M.; PASTORE, U.; COURA NETO, A. B. Vegetação. In: Atlas de Santa Catarina. Florianópolis: Gabinete do planejamento e Coordenação Geral, 1986. p.35-36.

KLEIN, R M. Espécies raras ou ameaçadas de extinção: Estado de Santa Catarina. Rio de Janeiro: IBGE, Diretoria de Geociências, 1990.

LINO, C. F. Reserva da Biosfera da Mata Atlântica. Campinas: Consórcio Mata Atlântica / Universidade Estadual de Campinas, 1991. v.1.

LISBOA, R.B.Z. Análise fitossociológica de uma comunidade arbórea, na Floresta Ombrófila Densa, no Parque Botânico Morro do Baú - Ilhota/SC. 2001. 122p. Dissertação (Mestrado em Biologia Vegetal) - Universidade Federal de Santa Catarina, Florianópolis, 2001.

LONGHI, S.J. et al. Aspectos fitossociológicos de fragmento de Floresta Estacional Decidual, Santa Maria, RS. Ciência Florestal, Santa Maria, v.10, n. 2, p. 59-74, 2000.

MANTOVANI, W. Estrutura e dinâmica da floresta atlântica na Juréia, Iguape - SP. 1983. Tese (Livre Docência) - Instituto de Biociências, Universidade de São Paulo, São Paulo, 1993 
ODUM, E.P. Ecologia. Rio de Janeiro: Ed. Guanabara, 1983.

PIELOU, E.C. Ecologycal diversity. London: Jonh Wiley, 1975. 165p.

QUEIROZ, M.H.de. Approche Phytoécologoque et Dynamique de Formation Végetales Secondaires Dévelopées Après Aband dês Activités Agricoles, dns lê Domaine de la Fôret Ombrophile Dense de Versant (Fôret Atlantique) à Santa Catarina - Brésil. 1994. 251p. Tese (Doutorando) - Ecole Nationale du Genie Rural, des Eaux et des Forests, Nancy - França, 1994.

REIS, A. et al. Curso: manejo do palmiteiro (Euterpe edulis) em regime de rendimento sustentado. Florianopolis: Universidade Federal de Santa Catarina, 1995. 84p.

SANTA CATARINA. SUDESUL/SAG. Levantamento de reconhecimento de solos do Estado de Santa Catarina.. Santa Maria, 1973. v.2.

SILVA, A.F. Composição florística e estrutura de um trecho de Mata Atlântica de encosta no município de Ubatuba-SP. 1980. 150p. Dissertação (Mestrado em Biologia Vegetal) - Universidade Federal de Campinas, Campinas, 1980.

SILVA, A. F.; LEITAO FILHO, H. F. Composição florística e estrutura de um trecho da mata atlântica de encosta no município de Ubatuba - SP. Revista Brasileira de Botânica, v.5, n.1/2, p. 43-52, 1982.

SIMINSKI, A. A Percepção dos agricultores da Microbacia Santa Filomena - São Pedro De Alcântara - SC, em relação aos remanescentes florestais da Mata Atlântica. 2002. 45p. Trabalho de Conclusão de Curso (Graduação) Curso de Agronomia - Universidade Federal de Santa Catarina, Florianopolis, 2002.

TABARELLI, M.; MANTOVANI, W. A regeneração de uma floresta tropical montana após corte e queima (São Paulo - Brasil). Rev. Brasil. Biol., v.59, n..2, p. 239-250, 1999.

VACCARO, S; LONGHI, S.J.; BRENA, D.A. Aspectos da composição florística e categorias sucessionais do estrato arbóreo de três subseres de uma Floresta Estacional Decidual, no Município de Santa Tereza-RS. Ciência Florestal, Santa Maria, v.8, n.1, p.1-18, 1999.

VELOSO, H.P.; RANGEL FILHO, A.L.R.R.; LIMA, J.C.A. Classificação da vegetação brasileira, adaptada a um sistema universal. Rio de Janeiro: IBGE, Departamento de Recursos Naturais e Estudos Ambientais, 1991. 124p.

VIANA, V.M.; TABANEZ A.J. Biology and conservation of forest fragments in Brazilian atlantic moist forest. In: SCHELHAS, J., GREENBERG, R. (Ed.). Forest patches: in tropical landscapes. Washington, D.C.: Island Press, p. 151-167, 1996. 